\title{
A case of severe hepatolithiasis after hepaticojejunostomy with Roux-en-Y reconstruction treated by endoscopic ultrasound-guided transhepatic antegrade stone removal
}

Balloon enteroscopy-assisted endoscopic retrograde cholangiopancreatography (ERCP) is useful for the treatment of bile duct stones in patients with surgically altered anatomy [1-3]; however, the procedure cannot always successfully remove stones when the anastomotic site or papilla of Vater cannot be reached. Recently, endoscopic ultrasound (EUS)guided antegrade intervention has been developed for benign biliary diseases, including hepatolithiasis in patients with altered anatomy $[4,5]$. We report a case of EUS-guided transhepatic antegrade stone removal (EUS-TASR) in a patient with altered anatomy ( $>$ Video 1 ).

The 59-year-old man underwent hepaticojejunostomy with Roux-en-Y reconstruction for hepatolithiasis several years previously. He was referred to our hospital for treatment of severe hepatolithiasis. Abdominal computed tomography showed huge impacted stones in the hilum and a dilated left intrahepatic bile duct ( $\triangleright$ Fig. 1 a).

We chose to perform EUS-TASR because accessing the anastomotic site by balloon-assisted ERCP was judged to be dif-

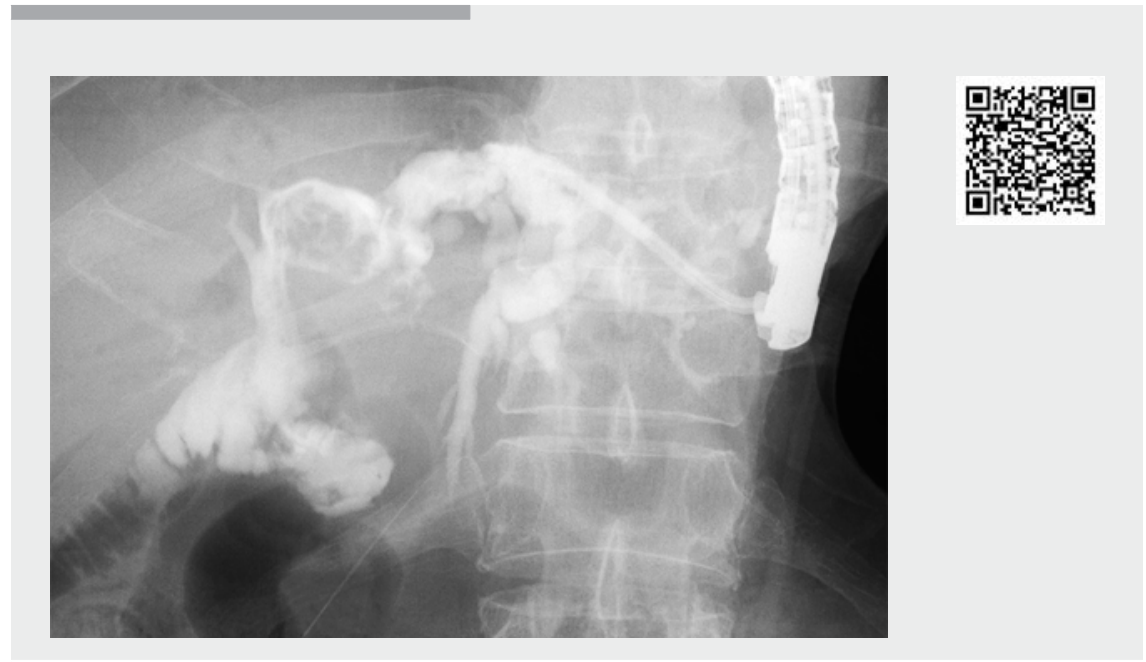

Video 1 Endoscopic ultrasound-guided transhepatic antegrade stone removal was useful for severe hepatolithiasis after hepaticojejunostomy with Roux-en-Y reconstruction.

ficult owing to the long afferent loop and because multiple sessions would be required for stone removal.

We first performed EUS-guided hepaticogastrostomy (EUS-HGS). The dilated left intrahepatic bile duct was punctured using a 19-gauge fine-needle aspiration needle from the residual stomach side. Cholangiography showed multiple impacted stones from the hilum to the bilateral intrahepatic bile ducts. A 0.025-inch guidewire was inserted into the intrahepatic bile duct and the needle tract was dilated using an ultra-tapered mechani-
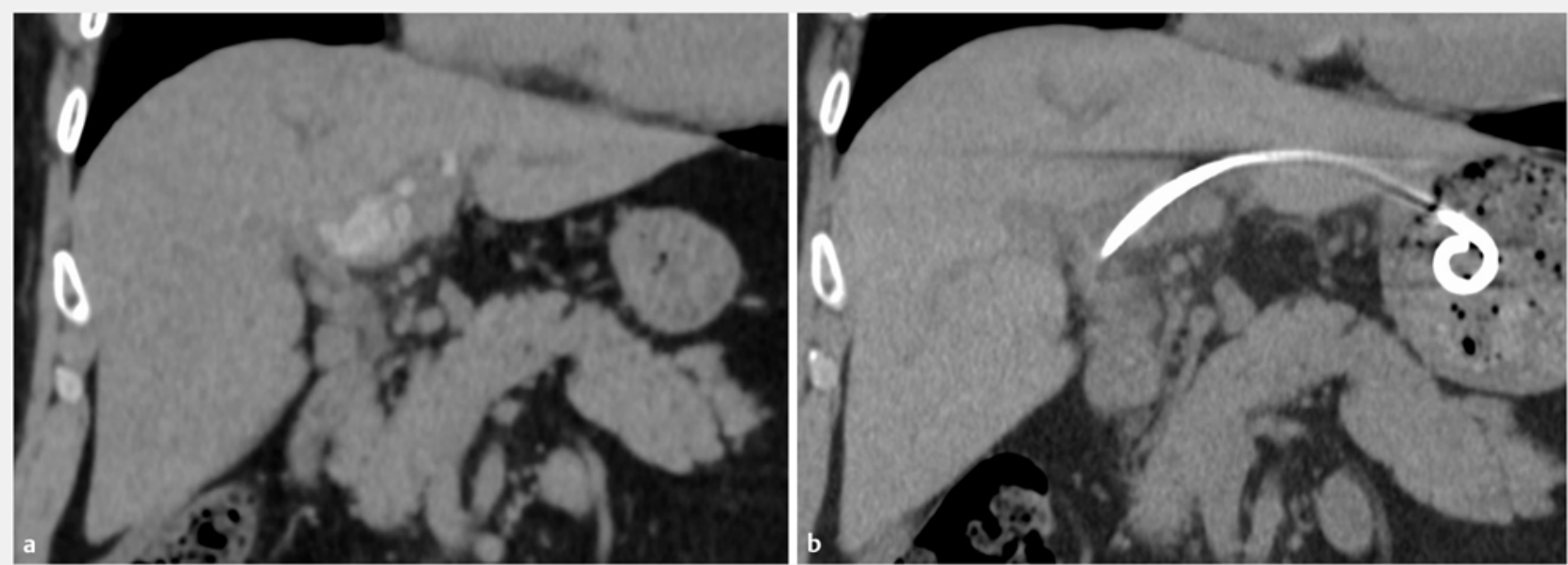

- Fig. 1 Computed tomography. a Before treatment, showing huge impacted stones in the hilum and a dilated left intrahepatic bile duct. b After the procedure, showing complete clearance. 


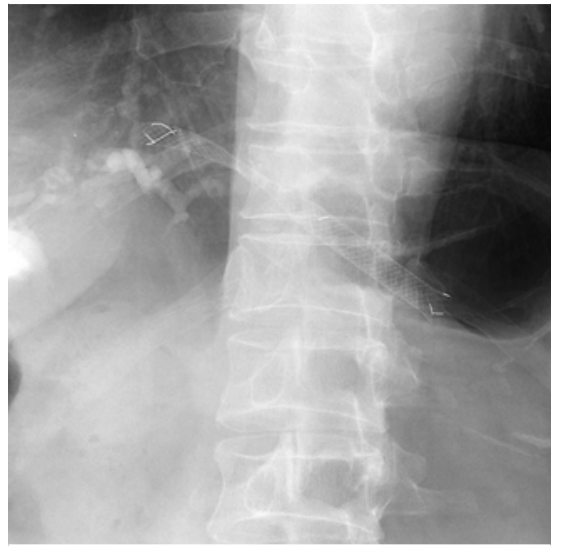

Fig. 2 Endoscopic ultrasound-guided hepaticogastrostomy.

cal dilator. A fully covered metal stent was then placed over the guidewire ( $\bullet$ Fig. $\mathbf{2}$ ). EUS-TASR was performed 1 month later. After dilation of the anastomotic stricture using a balloon catheter, a cholangioscope was inserted into the intrahepatic bile duct through the metal stent. Bile duct stones were crushed using electrohydraulic lithotripsy under direct visualization ( $\triangleright$ Fig.3). Subsequently, stone fragments were removed using a basket catheter and balloon catheter through the anastomotic route and HGS route ( $\triangleright$ Fig.4). Finally, the huge hepatic bile duct stone was completely removed ( Fig.1b).

Endoscopy_UCTN_Code_TTT_1AS_2AD

\section{Competing interests}

The authors declare that they have no conflict of interest.

The authors

Toshihiro Homma ${ }^{1}$, Kenjiro Yamamoto ${ }^{1}$, Takayoshi Tsuchiya ${ }^{1}$, Ryosuke Tonozuka', Hirohito Minami ${ }^{1}$, Eri Joyama ${ }^{2}$, Takao Itoi ${ }^{1}$

1 Department of Gastroenterology and Hepatology, Tokyo Medical University Hospital, Tokyo, Japan

2 Department of International medicine, Tokyo Medical University Hospital, Tokyo, Japan

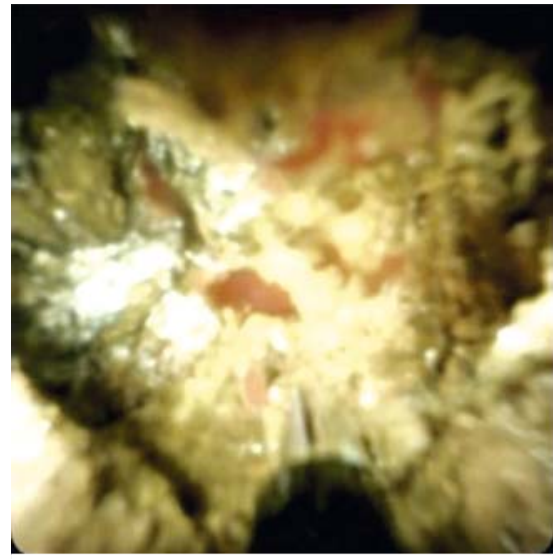

- Fig. 3 Bile duct stones were crushed using electrohydraulic lithotripsy under direct visualization.
Corresponding author

\section{Kenjiro Yamamoto, MD}

Department of Gastroenterology and Hepatology, Tokyo Medical University, 6-7-1, Nishishinjuku, Shinjuku-ku, Tokyo 160-0023, Japan

Fax: +81-3-53816654

ken.yamamoto5544@gmail.com

\section{References}

[1] Itoi T, Ishii K, Sofuni A et al. Long- and shorttype double-balloon enteroscopy-assisted therapeutic ERCP for intact papilla in patients with a Roux-en-Y anastomosis. Surg Endosc 2011; 25: 713-721

[2] Itokawa F, Itoi T, Ishii K et al. Single- and double-balloon enteroscopy-assisted endoscopic retrograde cholangiopancreatography in patients with Roux-en-Y plus hepaticojejunostomy anastomosis and Whipple resection. Dig Endosc 2014; 26: 136-143

[3] Ishii K, Itoi T, Tonozuka R et al. Balloon enteroscopy-assisted ERCP in patients with Roux-en-Y gastrectomy and intact papillae (with videos). Gastrointest Endosc 2016; 83: 377-386

[4] Itoi T, Sofuni A, Tsuchiya T et al. Endoscopic ultrasonography-guided transhepatic antegrade stone removal in patients with surgically altered anatomy: case series and technical review (with videos). J Hepatobiliary Pancreat Sci 2014; 21: E86-E93

[5] Mukai S, Itoi T, Sofuni A et al. EUS-guided antegrade intervention for benign biliary diseases in patients with surgically altered anatomy (with videos). Gastrointest Endosc 2019; 89: 399-407

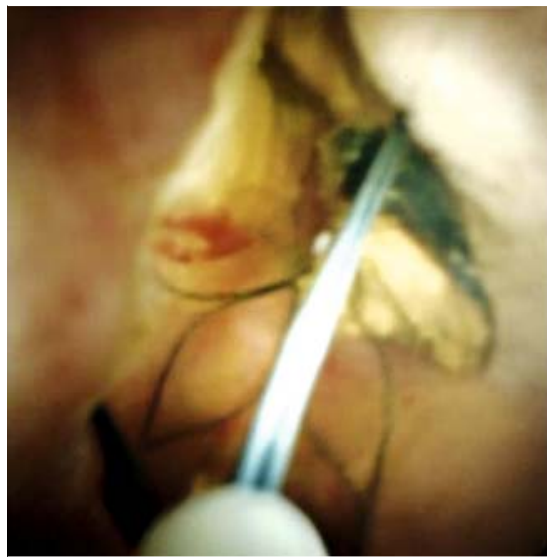

- Fig. 4 Stone fragments were removed using a basket catheter through the hepaticogastrostomy route under direct visualization.

Bibliography

Endoscopy 2021; 53: E230-E231

DOI 10.1055/a-1244-9556

ISSN 0013-726X

published online 23.9.2020

(c) 2020. Thieme. All rights reserved. Georg Thieme Verlag KG, Rüdigerstraße 14, 70469 Stuttgart, Germany

\section{CORRECTION}

A case of severe hepatolithiasis after hepaticojejunostomy with Roux-en-Y reconstruction treated by endoscopic ultrasound-guided transhepatic antegrade stone removal

Homma T, Yamamoto K, Tsuchiya T et al. A case of severe hepatolithiasis after hepaticojejunostomy with Roux-en-Y reconstruction treated by endoscopic ultrasound-guided transhepatic antegrade stone removal.

Endoscopy 2020, 52:

10.1055/a-1244-9556

In the above-mentioned article, the institution of Takao Itoi has been corrected. This was corrected in the online version on September 30, 2020. 